\title{
Os desafios urbanos e ambientais da Microbacia do Lageado no Itaim Paulista
}

Ana Paula Kourya,b, ${ }^{a}$ Filipe A. M. Falcettac, Nestor K. Yoshikawaa, Janilson O. Fernandesa, Rafael S. Pimentela, Mari Anna C. Firmino ${ }^{b}$, Pedro H. H. Correia ${ }^{b}$

a Programa de Pós-Graduação Stricto Sensu em Engenharia Civil, Universidade São Judas Tadeu, Taquari 546, São Paulo, Brasil, 03166-000.

b Programa de Pós-Graduação Stricto Sensu em Arquitetura e Urbanismo, Universidade São Judas Tadeu, Taquari 546, São Paulo, Brasil, 03166-000.

'Instituto de Pesquisas Tecnológicas do Estado de São Paulo, Av. Prof. Almeida Prado 532, São Paulo, Brasil, 05508-901.

\section{Informações}

Recebido 16 Maio 2021

Manuscrito revisado recebido

26 junho 2021

Aceito 29 Junho 2021

\section{Palavras-chave}

Desafios urbano-ambientais

Ribeirão do Lageado

Planejamento urbano

\section{Resumo}

Este artigo apresenta os desafios urbano e ambientais da Microbacia do ribeirão do Lageado no Itaim Paulista zona leste de São Paulo. Trata-se de uma área altamente urbanizada com edificações de padrão médio e baixo e assentamentos precários em áreas de risco. No exutório da Microbacia concentra-se muitos pontos de alagamento. Com base na política de ação climática da cidade de São Paulo discutimos as potencialidades da modelagem hidrológica para uma ação local no âmbito das atividades do Lab Itaim Paulista - Laboratório de Política Urbana e Planejamento Local da Universidade São Judas Tadeu.

\section{Environmental services and disservices associated with urban and periurban agriculture in the city of São Paulo}

\section{Article info}

Received 16 May 2021

Received in revised form 26 June 2021

Accepted 29 June 2021

\section{Keywords}

Urban and environmental challenges

Lageado river watershed

Urban planning

\section{Abstract}

This paper presents the urban and environmental challenges of the Lageado river watershed in Itaim Paulista, east of São Paulo. It is a highly urbanized area with medium and low standard buildings and precarious settlements in risky areas. Many flooding points are concentrated in the watershed outflow. Based on the climate action policy of the city of São Paulo, we discuss the potential of hydrological modeling for a local action within the activities of the Lab Itaim Paulista - Laboratory of Urban Policy and Local Planning at University São Judas Tadeu.

\section{Servicios y perjuicios ambientales asociados a la agricultura urbana y periurbana en la ciudad de São Paulo}

\section{Información}

Recibido 16 Mayo 2021

Manuscrito revisado recibido 26 Junio 2021

Aceptado 29 Junio 2021

\section{Palabras clave}

Desafíos urbano-ambientales

Cuenca del río Lageado

Urbanismo

\section{Resumen}

Este artículo presenta los desafíos urbanos y ambientales de la cuenca del río Lageado en Itaim Paulista, al este de São Paulo. Es una zona muy urbanizada con edificaciones de nivel medio y bajo y asentamientos precarios en zonas de riesgo. Muchos puntos de inundación se concentran en el desagüe de la microcuenca. A partir de la política de acción climática de la ciudad de São Paulo, discutimos el potencial de la modelización hidrológica para una acción local dentro de las actividades del Laboratorio Itaim Paulista - Laboratorio de Política Urbana y Planificación Local de la Universidad São Judas Tadeu.

\footnotetext{
* Autor correspondente em: Programa de Pós-Graduação Stricto Sensu em Engenharia Civil, USJT, Taquari 546, São Paulo, Brasil, 03166-000. 


\section{A Microbacia do Ribeirão do Lageado}

Os impactos ambientais decorrentes da urbanização da Microbacia do Ribeirão do Lageado são intensos. O diagnóstico dos problemas que afetam a área é complexo pois envolve muitos fatores. Destaca se neste contexto, a preservação dos mananciais e a gestão das águas como o grande desafio, para equacionar as ameaças naturais para manutenção da qualidade vida que afeta principalmente a população local. As diretrizes observadas pelas ações implementadas por meio de políticas públicas citadas neste artigo, carece de uma informação básica, que é o entendimento claro de como, o manancial se relaciona com o processo antrópico, principalmente na poluição e contaminação do manancial, nos aspectos do saneamento básico, sendo o mais crucial, o risco a alagamentos e enchentes, potencializado pelas mudanças climáticas. Entende se, portanto, que neste enfoque, o parâmetro técnico a ser integrado é a presença de água no local, caracterizado pelo volume de água na microbacia em função da vazão modelado através de um software especializado. O objetivo desse trabalho é contribuir para o desenvolvimento urbano local e para os planos regionais das subprefeituras, através do estudo da Microbacia do Ribeirão do Lageado considerando também a relevência de sua contribuição no manancial como um todo. Através desse estudo pretendemos oferecer subsídios para estabelecer critérios de minimização dos riscos, que podem ser incorporados como parâmetros de uso e ocupação e como diretrizes para o planejamento urbano.

A Microbacia do Ribeirão do Lageado faz parte do conjunto de contribuição do Alto Tietê. Há uma grande concentração de alagamentos registrados no exutório dessa bacia, conforme dados disponíveis na Plataforma Geosampa. Ocupa uma área de aproximadamente $11 \mathrm{~km}^{2}$, e $81 \%$ da microbacia localiza-se no município de São Paulo e 19\% em Ferraz de Vasconcelos, onde fica a nascente do Ribeirão. A maior parte da bacia encontra-se na região administrativa da Subprefeitura do Itaim Paulista (54\% nos distritos de Itaim Paulista e Curuça), e o restante localiza-se nas Subprefeituras de Guainazes (23\% no distrito do Lageado) e São
Miguel Paulista (4\% no distrito Jardim Helena).

Atualmente, 90\% da área da bacia encontra-se impermeabilizada e estima-se que abriga cerca de 153 mil habitantes. (Fernandes et. al., 2020) Embora praticamente toda impermeabilizada e densamente ocupada, a conformação geomorfológica do terreno permanece muito próxima da situação original. como demonstra a comparação do Mapa de Hipsometria dos modelos digitais de elevação com base nos levantamentos de 1930, 2004, 2011 e 2017.

A bacia encontra-se em grande parte ocupada por edificações residenciais horizontais de baixo padrão incluindo os loteamentos irregulares, núcleos e assentamentos precários ao longo do córrego como as favelas do Torresmo e do Jaraguá. Essas áreas coincidem com alto índice de vulnerabilidade social.



Fig. 1. Localização da Microbacia do Lageado nos distritos administrativos da cidade de São Paulo e em Ferraz de Vasconcelos (Fernandes et. al. 2020). 
O Ribeirão do Lageado flui paralelo à Estrada Dom João Nery. Este perímetro identificado pelo Caderno Perímetro de Ação IT (SMDU, 2016) que compõe o Plano Regional como ID 348 caracterizase pela diversidade, combina setores densamente povoados e de alta vulnerabilidade social, “(...) com grande quantidade de assentamentos precários em áreas de risco geológico, como os Jardins Jaraguá e Campos 1 e 2, às do Ribeirão Lageado, além de áreas mais bem estruturadas com forte caráter comercial local (...)" localizadas mais próximas a Av. Marechal Tito.

O corredor de ônibus do trecho III (Itaim Paulista - São Mateus) do sistema perimetral Leste 2 é um dos corredores prioritários que deveriam ter sido implantados em 2016 (SPTrans, 2013). Em função da implantação dessa infraestrutura, o perímetro foi enquadrado como uma Zona de Estruturação da Transformação Urbana e a estrada Don João

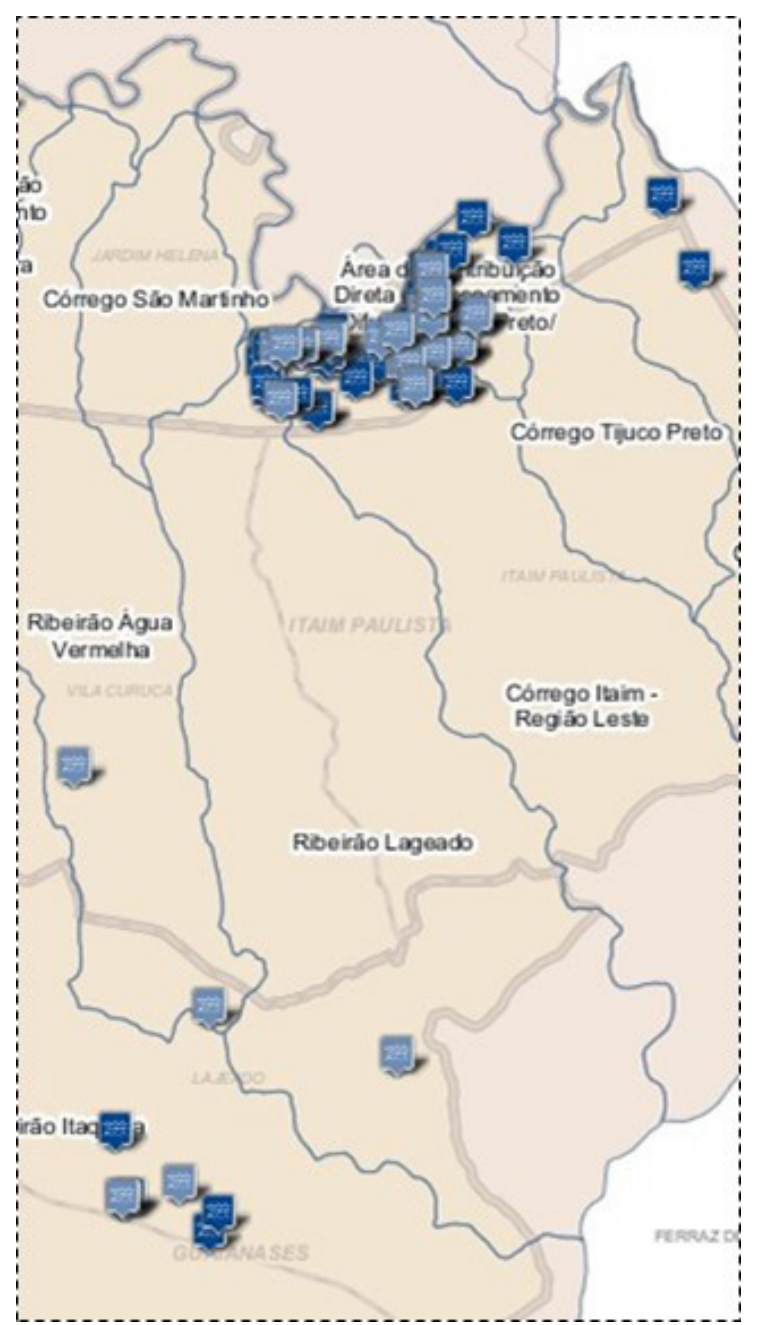

Fig. 2. Localização de Alagamentos no exutório da Microbacia do Lageado Fonte: Geosampa. Disponível em http:// geosampa.prefeitura.sp.gov.br/PaginasPublicas/_SBC.aspx. Acesso em 16/06/2021.
Nery será alargada para se transformar em um eixo de mobilidade metropolitana. A estrada abriga um setor residencial vulnerável ao sul e constitui uma importante centralidade local do Itaim Paulista à norte, onde funcionam vários comércios locais de pequeno e médio porte. Também fazem parte desse perímetro equipamentos públicos como uma Unidade Básica de Saúde e uma Escola Municipal. A área de desapropriação para as obras necessárias à instalação do corredor de ônibus causou a mobilização da população que, desde 2013, manifestou-se por diversas vezes contra o traçado do corredor previsto no PDE. (KOURY E CAVALLARI, 2018). Entre a estrada Don João Nery e o ribeirão do Lageado, o PDE também prevê a implantação do Parque Linear Ribeirão do Lageado na Subprefeitura do Itaim Paulista (SMDU, 2016: 22).

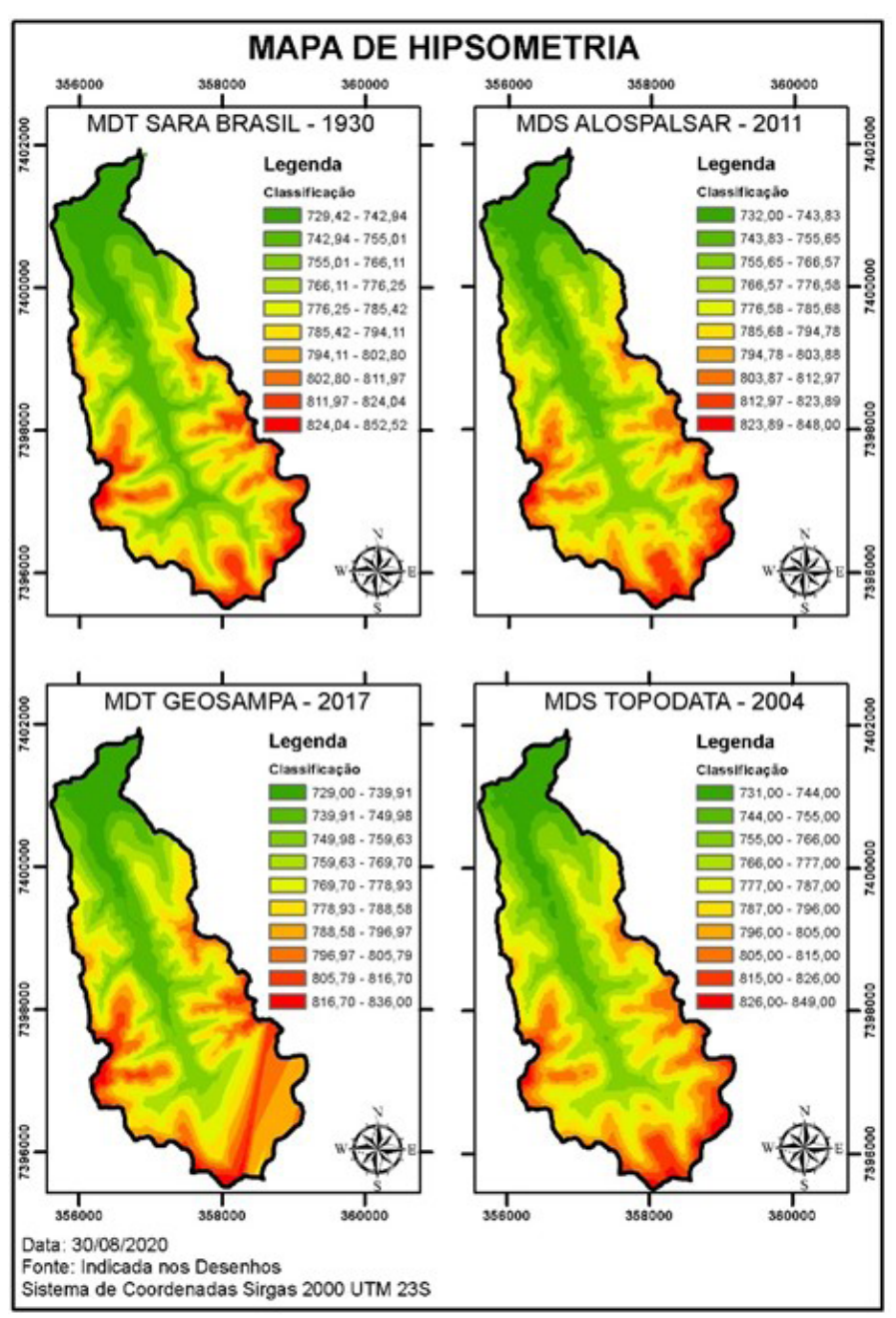

Fig. 3. Comparação dos mapas de hipsometria com base em levantamentos de 1930, 2004, 2011 e 2017. (Fernandes et. al. 2020). 


\section{O Plano de Ação Climática da Prefeitura de São Paulo}

Desde 2009 a cidade de São Paulo possui uma Política Municipal da Mudança do Clima estabelecida pela Lei 14.933 (São Paulo [cidade] 2009, 5 de junho) e conduzida por um Comitê de Mudança do Clima vinculado à Secretaria do Verde e do Meio Ambiente. A Política Municipal estabeleceu a obrigatoriedade de serem elaborados inventários de emissões de gases de efeito estufa (GEE) a cada cinco anos e estabeleceu como meta para o ano de 2012 "a redução de 30\% (trinta por cento) das emissões antrópicas (...) dos gases de efeito estufa listados no Protocolo de Quioto (...), em relação ao patamar expresso no inventário realizado pela Prefeitura Municipal de São Paulo e concluído em 2005.". Embora o último inventário apresentado em setembro de 2019 mostre um período de reduções das emissões de gases de efeito estufa a partir de 2014, a meta prevista pela Lei 14.933 não foi alcançada. Ainda em 2019 a Prefeitura

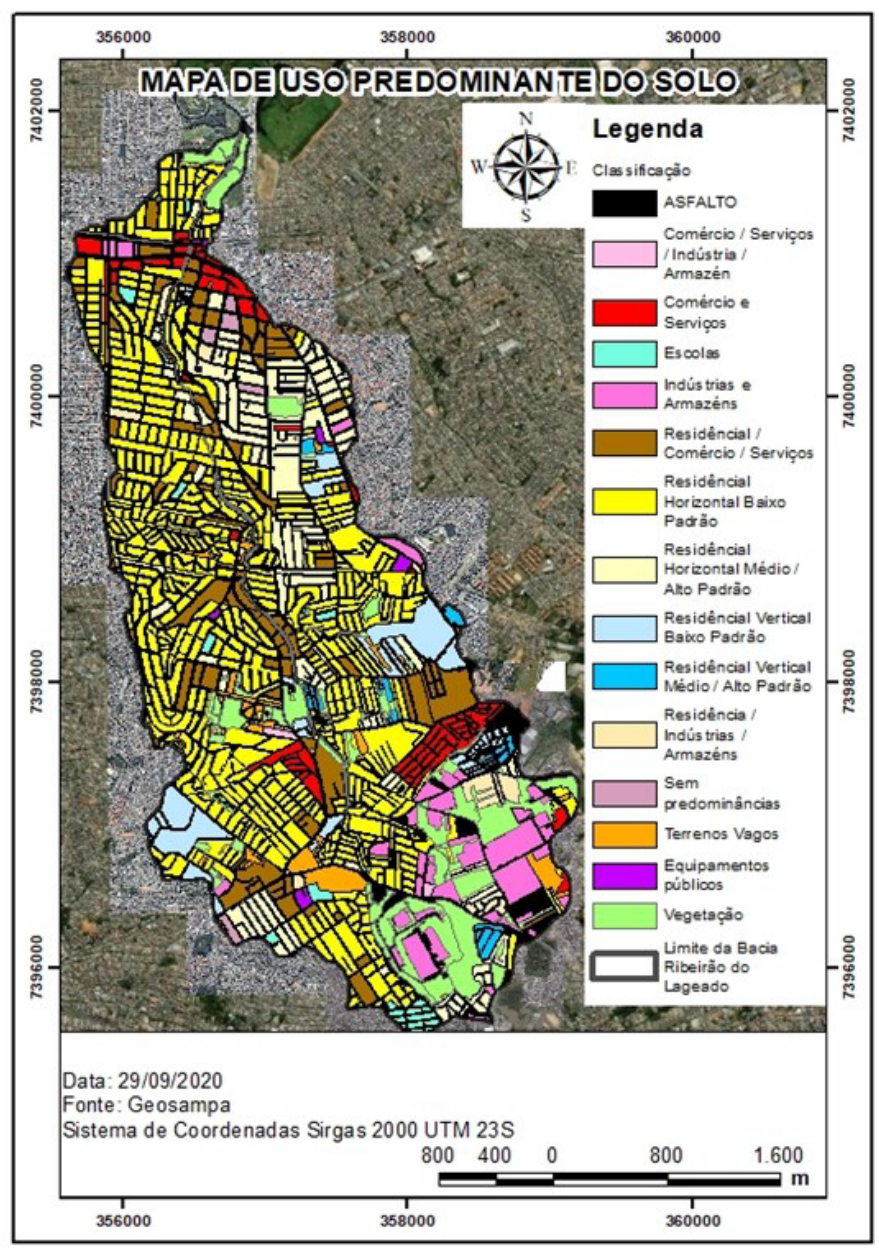

Fig. 4. Mapa de Uso e Ocupação do solo segundo a classificação de predominância de uso da PMSP (Fernandes et. al. 2020). de São Paulo instituiu um Grupo de Trabalho Intersecretarial (GTI) para elaborar um Plano de Ação Climática a ser desenvolvido no âmbito da rede internacional de cidades C40 - Grandes Cidades para a Liderança Climática - que São Paulo é uma das cidades fundadoras. Esse Plano, recém finalizado, inclui não apenas o controle das emissões de gases de efeito estufa, mas também considera as ações necessárias para a adaptação da cidade aos impactos dos eventos extremos causados pela mudança do clima que recai sobre a população mais vulnerável da cidade.

A Prefeitura de São Paulo tem adotado medidas importantes no sentido de dirigir o sistema de planejamento municipal em direção ao desenvolvimento sustentável. A Lei Municipal $n^{\circ}$ 16.773 (São Paulo [cidade], 201727 de dezembro) que dispõe sobre o Plano Plurianual para o quadriênio 2018/2021 vincula "o Programa de Metas 2017-2020 e a Agenda 2030 da ONU" e, posteriormente, a Lei Municipal n ${ }^{0} 16.817$ (São Paulo [cidade], 2018, 2 de fevereiro) selou o compromisso da prefeitura de São Paulo em adotar a Agenda 2030. Outra iniciativa importante nesse sentido é a adesão da cidade de São Paulo à iniciativa internacional Open Government Partnership (OGP) que reúne 14 governos subnacionais como Austin (EUA), Buenos Aires (Argentina), Madrid (Espanha), Seul (Coreia do Sul), Sekondi-Takoradi (Gana), Bojonegoro (Indonesia) entre outros. Este compromisso internacional assegura os valores de transparência, inovação, participação social e accountability na gestão pública municipal em São Paulo.

Uma das ações para responder aos compromissos do Governo Aberto da Cidade de São Paulo foi a implementação do Plano de Ação das Subprefeituras. Esse plano pretendeu responder à lacuna do sistema de planejamento da cidade através do fortalecimento dos planos regionais (São Paulo [cidade], 2016, 16 de dezembro) e planos de bairro, que embora integrem a legislação municipal, (Lei 16.050/2014) os primeiros foram apenas parcialmente implantados e os últimos não chegaram a ser elaborados. Esses dois níveis do planejamento são os que mais representam 
demandas locais e mobilizam o processo participativo. Por esse motivo são elementos estratégicos que fortalecem os princípios de participação e transparência na gestão municipal.

Para a elaboração dos Planos de Ação das Subprefeituras, o primeiro trabalho realizado em agosto de 2019 pela Coordenadoria de Planejamento Urbano (PLANURBE) da Secretaria Municipal de Desenvolvimento Urbano foi o levantamento detalhado de todas as ações já realizadas, as ações em andamento e as ações já previstas no orçamento de 2020, em todas as subprefeituras da cidade de São Paulo. O objetivo foi produzir um quadro diagnóstico para identificar possíveis lacunas para o atendimento das demandas locais registradas nos Planos Regionais de 2016, que, eventualmente, poderiam ainda ser atendidas em 2020, mas, sobretudo, criar as condições prévias para o ciclo de revisão participativa do PDE e Planos Regionais previsto para ser iniciado este ano de 2021.

Nessa fase, foi solicitado que as Subprefeituras indicassem perímetros prioritários de intervenção. A Subprefeitura do Itaim Paulista elegeu o perímetro ID 348 da Estrada Dom João Nery na microbacia do Lageado como um dos perímetros prioritários de intervenção, demonstrando a importância estratégica desse perímetro de estudo para a localidade do Itaim Paulista.

\section{Modelos hidrológicos e Transformação Local no Itaim Paulista}

O Itaim Paulista tem sido objeto de estudo do Lab Itaim Paulista desde 2015, quando a área foi case study do workshop "planning by conflicts" parte das atividades da pesquisa "Planning and participation: a new agenda for urban and environmental policies in Brazil" (Fapesp 13/ 50918-4), uma colaboração entre a Universidade São Judas Tadeu e a Universidade do Texas. (LARA \& KOURY, 2016). O último workshop do projeto realizado em 2016 resultou na proposição de um convênio entre a Secretaria Municipal de Desenvolvimento Urbano (SMDU) e a Universidade São Judas Tadeu, com foco no monitoramento do Plano Regional, no estudo de estratégias de educação ambiental baseadas em situações-problema locais e na oferta de um curso de capacitação para os gestores locais (São Paulo [cidade], 201624 de dezembro).

Desde então, além dos produtos desenvolvidos no âmbito do convênio com a SMDU, o Lab Itaim Paulista desenvolveu várias ações locais, como a Gincana na Casa de Cultura em 2017, e duas ações realizadas na Escola Dama entre Rios Verdes em 2019. Em 2018 o Lab Itaim Paulista integrou o projeto "São Paulo City Lab: Towards a Joint Research Laboratory for Integrated Environmental and Climatic Assessment of São Paulo" (Fapesp 17/50076-4). O projeto teve como objetivo principal formar uma equipe interdisciplinar e estabelecer em base científica, a capacidade de previsão integrada de eventos ambientais adversos "que colocarão em risco as populações dentro e ao redor da RMSP". A equipe formada pelo projeto, era composta por pesquisadores brasileiros e alemães, concentrava-se na ciência do clima (química e física atmosférica), na modelagem computacional dos eventos climáticos (aerossóis e hidrologia) e no planejamento urbano local. Agregou o conhecimento sobre o sistema do clima de institutos de pesquisa como o Instituto de Astronomia, Geofísica e Ciências Atmosféricas IAG USP (São Paulo) e o Max Planck Institute for Metereology MPI (Hamburg) com os estudos urbanos realizados em São Paulo no âmbito da colaboração pregressa da HafenCity University (Hamburgo) e do Instituto de Arquitetura e Urbanismo (USP São Carlos) (projeto DAAD/2013) e da consolidação dos estudos locais na área do Itaim Paulista, realizado pelo Lab Itaim Paulista da Universidade São Judas Tadeu (LARA \& KOURY, 2016). O projeto agregou uma equipe de pesquisadores e promoveu um conjunto de seminários como estratégia para integrar a modelagem computacional com os estudos urbanos, contribuindo para unir a compreensão do processo global da crise climática com ações estratégicas que possam ter grande impacto local.

Com a criação do Laboratório Klimapolis (IAG USP- MPI Hamburg), em 2019, os estudos urbanos em andamento no projeto "São Paulo City Lab" passaram a compor o novo laboratório. 
O Laboratório Klimapolis foi criado com ênfase nos estudos sobre governança ambiental integrados às ciências básicas que estavam em andamento no Brasil, liderado pelo Prof. Dr. Pedro Jacobi (Instituto de Energia e Ambiente IEE USP) e na Alemanha, liderado pela Profa. Dra. Anita Engels (Universidade de Hamburgo UHH).

No encontro de maio de 2019, o Laboratório Klimapolis elegeu o Itaim Paulista para ser o piloto de um experimento de transformação local. No escopo dessa parceria o Lab Itaim Paulista estabeleceu uma nova fase de cooperação com a SMDU e com a Subprefeitura do Itaim Paulista. Desenvolveu três ações locais, duas ações na Escola Dama entre Rios Verdes, e uma ação na comunidade do Torresmo (bacia do Lageado).

Entre demais ações do Lab Itaim Paulista destacase a organização de um curso de modelagem hidrológica (com duração de 45 horas) com foco na microbacia do Lageado. O Curso só foi possível graças à colaboração com o Instituto de Pesquisas Tecnológicas do Estado de São Paulo (IPT), com a São Paulo Urbanismo e com a Subprefeitura do Itaim Paulista. Permitiu reunir técnicos de diferentes setores da administração municipal em um debate cientificamente informado sobre a situação problema da microbacia do ribeirão Lageado. Neste curso foi estimada a vazão de enchente da referida microbacia considerando a aplicação do método do Hidrograma Unitário por meio da utilização do software HEC-HMS.

O software HEC-HMS (Hydrologic Modeling System) foi desenvolvido pelo Hydrologic Engineering Center do corpo de engenheiros do exército norte-americano, e permite simular processos chuva-vazão em bacias hidrográficas dendríticas valendo-se de inúmeros modelos apresentados pela literatura.

O programa é aplicável em muitas situações: desde análises de cheias em grandes bacias, até mesmo na determinação de vazões em sistemas de microdrenagem em pequenas bacias urbanas.

No curso de modelagem hidrológica, a microbacia do ribeirão Lageado foi modelada considerando-se três cenários de ocupação: situação da ocupação em 1930 (levantamento SARA Brasil, 1930); situação atual (90\% de impermeabilização); cenário ideal, respeitando a Área de Preservação Permanente junto ao Ribeirão do Lageado (com recuo de 30 metros em cada uma das margens), adotando a cobertura asfáltica com concreto permeável em toda a bacia e também a adoção de sistema infiltrado de microdrenagem nos lotes urbanos. No quarto e último cenário adotou-se uma estratégia realista baseada nas oportunidades de intervenção e regulação para uma política de desenvolvimento urbano que prioriza os dispositivos de micro e macrodrenagem. Os resultados foram estimulantes e permitiram antever a potencialidade de estudos aprofundados que combinem modelagem computacional, regulação do desenvolvimento e governança local para enfrentar os desafios colocados na situação-problema piloto da microbacia do Lageado no Itaim Paulista.

Um grande desafio para a melhoria destas áreas, densamente ocupadas por população de baixa renda e sem grandes investimentos do Estado, é a condição de sobrevivência da microbacia, como contribuinte do manancial do Alto Tietê. A determinação da vazão utilizando métodos mais precisos, auxilia na compreensão de como este parâmetro está relacionado ao potencial de risco de uso e ocupação das populações nas áreas de influência da microbacia. A aplicação de diferentes diretrizes estabelecidas pelas políticas públicas, que tem sido analisada nos programas e estudos citados neste artigo, permite estabelecer uma relação entre os locais vulneráveis a alagamentos, com os estudos de impactos ambientais na região, que afetam a preservação dos mananciais e são fatores de risco para a população dessas localidades. Assim o grande desafio é a integração de informações entre os dados hidrológicos que demonstram como a microbacia tem sido afetada pela urbanização, quais seriam as oportunidades de ensaiar um novo modelo de planejamento urbano que contribua para a resiliência dos assentamentos vulneráveis frente aos eventos extremos que tendem a piorar a ocorrência de enchentes e alagamentos na região do Alto Tietê. 


\section{Referências bibliográficas}

FERNANDES, J. O. et. al. Obtenção e elaboração de dados para aplicação do método do diagrama unitário na bacia ribeirão do Lageado pelo HECHMS. Monografia (Graduação em Engenharia Civil) - Universidade São Judas Tadeu, São Paulo, 2020.

KOURY, A. P.; CAVALLARI, T. V. Desenvolvimento urbano em áreas de fronteira: o caso do Itaim Paulista. Urbe, Rev. Bras. Gest. Urbana, v. 10, n. 3, p. 663-676, 2018.

\section{LARA, F.; KOURY, A. P. (Ed.). Planejamento versus}

Participação: um falso dilema. Austin: nhámerica, 2016.

São Paulo (Cidade) (2009, 5 de junho). Lei $\mathbf{n}^{\circ}$ 14.933. "Institui a política de mudança do clima no município de São Paulo". Diário Oficial do Município 06/06/2009.

São Paulo (Cidade) (2016, 16 de dezembro). Decreto 57.537/2016. "Regulamenta os artigos 344 a 346 da Lei $n^{0}$ 16.050, de 31 de julho de 2014 - Plano Diretor Estratégico, instituindo os Planos Regionais das Subprefeituras, elaborados a partir dos princípios e diretrizes nele estabelecidos, articulado à revisão da nova disciplina de parcelamento, uso e ocupação do solo instituída pela Lei $n^{0}$ 16.402, de 22 de março de 2016; bem como orienta a elaboração e aplicação dos Planos de Ação das Subprefeituras". Diário Oficial do Município 17/12/2016, p.1.

São Paulo (Cidade) (2016, 24 de dezembro). Despacho do gabinete 2016-0.188.817-8. SMDUSecretaria Municipal de Desenvolvimento Urbano e AMC Serviços Educacionais (Universidade São Judas Tadeu). Convênio. Diário Oficial do Município 24/12/2016 p. 20 [São Paulo 61 (241)]

São Paulo (Cidade) (2017, 27 de dezembro). Lei n' 16.773. "Dispõe sobre o Plano Plurianual para o quadriênio 2018/2021". Diário Oficial do Município 28/12/2017, p.3.
Lei n' 16.817. "Adota a Agenda 2030 para o Desenvolvimento Sustentável da Organização das Nações Unidas (ONU) como diretriz de políticas públicas em âmbito municipal, institui o Programa de sua implementação, autoriza a criação da Comissão Municipal para o Desenvolvimento Sustentável (Agenda 2030) e dá outras providências.". Diário Oficial do Município 03/2/2018, p.1.

São Paulo (Cidade). (2014, 1 de agosto). Lei $\mathbf{n}^{\circ}$ 16.050/2014 de 31 de julho de 2014. Aprova a Política de Desenvolvimento Urbano e o Plano Diretor Estratégico do Município de São Paulo e revoga a Lei $n^{0}$ 13.430/2002. São Paulo: Diário Oficial Cidade de São Paulo, ano 59, n. 140 (suplemento).

SMDU - Secretaria Municipal de Desenvolvimento Urbano. Caderno Perímetro de Ação Itaim Paulista. São Paulo: Secretaria Municipal de Desenvolvimento Urbano, 2016.

SPTrans - Secretaria Municipal de Transportes. Terminais e Sistemas Viários - Região Leste 2. Estudo de Impacto Ambiental. Processo Administrativo no. 2013-0.202.378-7, 2013.

São Paulo (Cidade) (2018, 2 de fevereiro). 